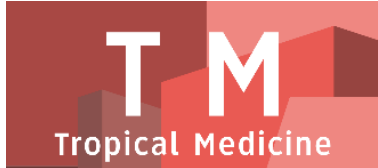

PAPER - OPEN ACCESS

\title{
Formulasi dan Evaluasi Nanoemulsi dari Extra Virgin Olive Oil (Minyak Zaitun Ekstra Murni) sebagai Anti-Aging
}
Author
: Nurul Anisha Hakim
DOI
: 10.32734/tm.v1i2.222
Electronic ISSN
: 2623-0550
Print ISSN
: 2623-0542

Volume 1 Issue 2 - 2018 TALENTA Conference Series: Tropical Medicine (TM)

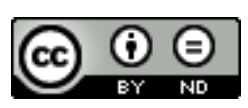

This work is licensed under a Creative Commons Attribution-NoDerivatives 4.0 International License.

Published under licence by TALENTA Publisher, Universitas Sumatera Utara
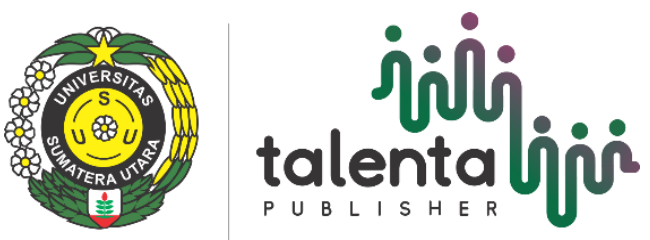


\title{
Formulasi dan Evaluasi Nanoemulsi dari Extra Virgin Olive Oil (Minyak Zaitun Ekstra Murni) sebagai Anti-Aging
}

\author{
Nurul Anisha Hakima ${ }^{\mathrm{a}}$, Anayanti Arianto $^{\mathrm{a}}$,Hakim Bangun ${ }^{\mathrm{a}}$ \\ Fakultas Farmasi, Universitas Sumatera Utara 20155, Indonesia \\ nurulalthafunnisha@gmail.com
}

\begin{abstract}
Abstrak
Minyak zaitun ekstra murni mengandung berbagai antioksidan dan vitamin E yang mencegah penuaan kulit. Nanoemulsi yang mengandung minyak zaitun ekstra murni merupakan cara yang efektif untuk pelepasan bahan aktif dikarenakan ukuran dropletnya yang kecil, dan dapat dengan mudah berpenetrasi ke dalam kulit. Tujuan dari penelitian ini adalah untuk memformulasi dan mengevaluasi nanoemulsi minyak zaitun sebagai anti-aging.nanoemulsi anti-aging dibuat dari tiga formula menggunakan minyak zaitun ekstra murnidan variasi konsentrasi tween 80 dan sorbitol yaitu formula F1 (24\% dan $36 \%$ ); F2 (25\% dan 35\%); and F3 (26\% dan 34\%). Kemudian dilakukan uji stabilitas terhadap sediaan nanoemulsi tersebut selama penyimpanan 12 minggu pada suhu kamar dan ditentukan perbandingan aktivitas anti-aging dari sediaan nanoemulsi and emulsi. Hasil menunjukkan bahwa nanoemulsi minyak zaitun ekstra murni berwarna jernih dan transparan. Stabiltas dari nanoemulsi menunjukkan bahwa formula F2 adalah yang paling stabil selama penyimpanan 12 minggu pada suhu kamar, tidak terdapat perubahan pada uji sentrifugasi dan mempunyai ukuran droplet yang paling kecil (189,82 $\mathrm{nm})$ dan aktivitas anti-aging nya lebih baik dibandingkan dengan emulsi setelah pemakaian sediaan selama 4 minggu.
\end{abstract}

Kata kunci: Minyak zaitun ekstra murni, anti-aging,nanoemulsi

\section{Pendahuluan}

Penuaan kulit adalah proses biologis yang kompleks dipengaruhi oleh faktor intrinsik (hormon, genetik, dan metabolisme sel) dan faktor ekstrinsik (bahan kimia, paparan cahaya kronis, polusi, radiasi pengion, dan toxin)[1]. Salah satu sumber antioksidan alami adalahminyak zaitunyang terbukti dapat memberikan perlindungan terhadap terjadinya penuaan. Minyak zaitun mempunyai peranan penting dalam industrikosmetikkarena diyakini berkhasiat untuk menjaga kelembapan dan kelembutan kulit,sehingga kulit tetap awet muda. Hal ini dikarenakan sebagian besar komposisi minyak zaitun mengandung asam lemak tak jenuh, (oleat, linoleat, dan asam linolenat), mikronutrien vitamin (A, E, dan ß-karoten) dan antioksidanfenolik, yaitu hydroxytyrosol, tyrosol, oleuropein, lignan,serta squalene $[2,3,4,5]$.

Anti-aging merupakan bagian dari kosmetik yang mengandung bahan untuk mengurangi kerutan (wrinkle)dan meningkatkan level kelembaban (moisture) dari kulit. Fungsi utama dari sediaan anti-aging adalah mengurangi kerutan (wrinkle) dan bintik noda (spot). Dalam kosmetikanti-aging, yang menjadi perhatian utama adalah untuk mencapai sel kulit[1]. Sistem penghantaran kosmetik yang inovatif yang digunakan pada produk kosmetik salah 
satunya adalah nanoemulsi. Nanoemulsi atau miniemulsi adalah dispersi halus minyak/air atau air/minyak yang distabilkan oleh film antarmuka molekul surfaktan yang memiliki rentang tetesan 20-600 $\mathrm{nm}[6]$.

Teknologi nanoemulsi sangat menarik untuk diaplikasikan dalam kosmetik dikarenakan sifat estetika dari nanoemulsi yaitu stabil,viskositas yang rendah dan aspek visual yang transparan, serta luas permukaan yang tinggi memungkinkan penghantaran yang efektif dan dapat meningkatkan penetrasi dari bahan aktif untuk kulit. Pada penelitian sebelumnya, Asmarani (2015) melakukan penelitian tentang pembuatan nanoemulsi minyak zaitun ekstra murni dengan variasi konsentrasi tween 80 dan sorbitol dan pengujian terhadap aktivitas antioksidan minyak zaitun. Pada penelitian tersebut menghasilkan nanoemulsi minyak zaitun ekstra murni yang jernih dan transparan dan mempunyai nilai $\mathrm{IC}_{50}$ sebesar $55,79 \mathrm{ppm}$. Namun pada penelitian tersebut belum dilakukan evaluasi terhadap sediaan dan belum dilakukan uji aktivitas aniti-aging pada sediaan. Oleh karena itu, selanjutnyaminyak zaitun ekstra murni akandikembangkan dalambentuk sediaan nanoemulsi dan dilakukan evaluasi terhadap stabilitas dan aktivitas anti-aging dari sediaan tersebut.

\section{Lokasi dan Metode Penelitian}

\subsection{Lokasi Penelitian}

Penelitian ini dilakukan di Laboratorium farmasi fisik, Laboratorium kosmetologi, dan Laboratorium penelitian Fakultas Farmasi Universitas Sumatera Utara.

\subsection{Metode}

Penelitian ini dilakukan dari Juli 2016 sampai dengan April 2017. Alat yang digunakan pada penelitian ini adalah magnetic stirrer (WINA Instrument), sonikator (Branson), viskometer Brookfield DV-E, pH meter (Hanna Instrument), alat sentrifugasi (Hitachi CF 16 R X II), Vascoyparticle size analyzer, skin analizer (Aramo SG), moisture checker (Aramo SG),TEM (JEOL JEM 1400). Bahan yang digunakan pada penelitian ini adalah minyak zaitun ekstra murni, tween 80 , sorbitol, metil paraben, propil paraben aquadestilata.

Formulasi dan pengamatan organoleptis sediaan

Pada penelitian ini dibuat formulasi sediaan nanoemulsi dan emulsi dari minyak zaitun ekstra murni. Sediaan nanoemulsi dibuat menjadi tiga formula berdasarkan hasil orientasi, sedangkan sediaan emulsi dibuat satu formula yang digunakan hanya sebagai pembanding. Adapun komposisi formula nanoemulsi dapat dilihat pada Tabel 1.

Tabel 1. Komposisi formula Nanoemulsi

\begin{tabular}{|c|c|c|c|}
\hline \multirow{2}{*}{ Bahan } & \multicolumn{3}{|c|}{ Formula } \\
\cline { 2 - 4 } & I $(\mathbf{\%} \mathbf{b} / \mathbf{b})$ & II (\%)/b) & III (\%) b/b) \\
\hline Minyak Zaitun Ekstra Murni & 5 & 5 & 26 \\
\hline Tween 80 & 24 & 25 & 34 \\
\hline Sorbitol & 36 & 0,1 & 0,1 \\
\hline Metil Paraben & 0,1 & 0,02 & 0,02 \\
\hline Propil paraben & 0,02 & 100 & 100 \\
\hline Aquadestilata ad & 100 & & \\
\hline
\end{tabular}

Cara pembuatan:

Minyak zaitun ekstra murni dicampurkan dengan sorbiol (fase minyak). Selanjutnya dilarutkan metil paraben dan propil paraben ke dalam aquadestilata yang telah dipanaskan, lalu ditambahkan tween 80 ke dalam larutan tersebut (fase air) dan kemudian diaduk dengan magnetic stirrer pada kecepatan 3000-4000 rpm. Kemudian ditambahkan fase minyak sedikit-demi sedikit ke dalam fase air dan dicampurkan kedua fase tersebut dengan menggnakan magnetic stirrer selama 6 jam pada suhu ruang hingga terbentuk larutan yang jernih dan transparan. Kemudian 
dilakukan pengamatan organoleptis sediaan yang dilakukan secara penginderaan terhadap perubahan warna, bau, bentuk, pembentukan creaming, dan pemisahan fase selama 12 minggu pada penyimpanan suhu kamar.

Penentuan $\mathrm{pH}$ dan viskositas

Penentuan $\mathrm{pH}$ sediaan dilakukan dengan menggunakan alat $\mathrm{pH}$ meter.Alat terlebih dahulu dikalibrasi. Sampel dibuat dalam konsentrasi 1\% kemudiaan elektroda dicelupkan dalam larutan tersebut. Dibiarkan alat menunjukkan harga $\mathrm{pH}$ sampai konstan. Angka yang ditunjukkan $\mathrm{pH}$ meter merupakan $\mathrm{pH}$ sediaan [7]. Pengukuran viskositas dilakukan dengan menggunakan viskometer Brookfield. Sampel diletakkan dalam gelas beaker, dipilih spindel yang sesuai dan kemudian alat dijalankan. Hasil pengukuran diperoleh dengan cara mengalikan skala yang terbaca pada alat dengan faktor koreksi. Pengukuran dilakukan sebelum dan setelah penyimpanan selama 12 minggu pada suhu kamar.

Uji Sentrifugasi

Sediaan diisikan ke dalam tabung sentrifugasi kemudian diletakkan ke dalam alat sentrifugasi dan disentrifugasi dengan kecepatan 3750 rpm selama 5 jam.

Penentuann ukuran partikel dan analisa TEM

Ukuran partikel ditentukan dengan Vasco ${ }^{\gamma}$ CORDOUAN Technologies Particle Size Analyzer. Penentuan ukuran partikel dilakukan pada 0 minggu, 6 minggu, dan 12 minggu pada suhu kamar. Penentuan analisa partikel sediaan dilakukan dengan menggunakan alat Transmission Electron Scanning (TEM).

Uji efektivitas anti-aging

Pengujian efektivitas dilakukan terhadap sukarelawan sebanyak 6 orang dan dibagi menjadi dua kelompok uji. Semua sukarelawan diukur kondisi awal kulit pada area uji yang telah ditandai yang meliputi pori (pore), dan noda (spot) dengan menggunakan skin analyzer serta kadar air (moisture) diukur dengan menggunakan moiture checker. Perawatan mulai dilakukan dengan mengaplikasikan sediaan nanoemulsi dan emulsi minyak zaitun ektra murni pada wajah, diaplikasikan sebanyak 2 kali berdasarkan kelompok yang telah ditetapkan di atas selama 30 menit setiap hari. Perubahan kondisi diukur saat setelah aplikasi nanoemulsi dan emulsi setiap minggu selama 4 minggu dengan menggunakan alat skin analyzer.

\section{Hasil dan Pembahasan}

\subsection{Hasil}

Pada formulasi sediaan diperoleh hasil bahwa semua sediaan nanoemulsi yang terbentuk adalah berwarna kuning jernih dan transparan dan sediaan emulsi yang terbentuk adalah berwarna putih.

Berdasakan pengamatan organoleptis sediaan diperoleh hasil bahwa formula 2 dan formula 3 pada sediaan nanoemulsi tetap stabil hingga 12 minggu penyimpanan pada suhu kamar, tidak terjadi perubahan secara oganoleptis. Namun pada formula 1 terjadi pembentukan creaming. Hal ini dapat dilihat pada Gambar1 dan Gambar 2.
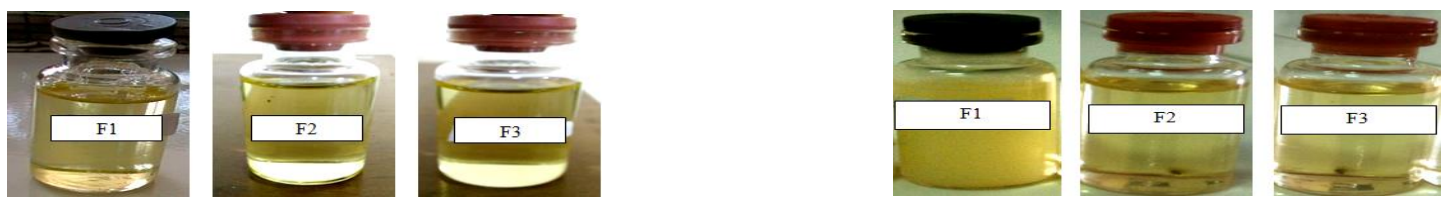

Gambar 1. a. Sediaan nanoemulsi F1, F2, dan F3 pada awal pembuatan sediaan pada suhu kamar, b. Sediaan nanoemulsi F1, F2, dan F3 pada saat penyimpanan 12 minggu pada suhu kamar.

Hasil penentuan $\mathrm{pH}$ dan viskositas

Selamapenyimpanan semua formula dari nanoemulsi mengalami sedikit penurunan $\mathrm{pH}$ dan kenaikan viskositas. Hasil penentuan $\mathrm{pH}$ dan viskositas dari sediaan nanoemulsi tersebut dapat dilihat pada Tabel 2 dan Tabel 3. 
Tabel 2. Data pengukuran pH nanoemulsi pada penyimpanan selama 12 minggu suhu kamar

\begin{tabular}{|l|l|l|l|l|l|l|l|l|l|l|l|l|l|}
\hline \multirow{2}{*}{ Formula } & \multicolumn{10}{|c|}{ waktu (minggu) } \\
\cline { 2 - 39 } & 0 & 1 & 2 & 3 & 4 & 5 & 6 & 7 & 8 & 9 & 10 & 11 & 12 \\
\hline F1 & 6,8 & 6,8 & 6,7 & 6,7 & 6,6 & 6,6 & 6,5 & 6,4 & 6,3 & 6,2 & 6,0 & 5,9 & 5,8 \\
\hline F2 & 6,2 & 6,2 & 6,1 & 6,1 & 6,0 & 6,0 & 5,9 & 5,5 & 5,3 & 5,2 & 5,1 & 5,0 & 4,9 \\
\hline F3 & 5,8 & 5,8 & 5,5 & 5,5 & 5,4 & 5,3 & 5,2 & 5,1 & 5,0 & 4,9 & 4,8 & 4,7 & 4,6 \\
\hline
\end{tabular}

Tabel 3. Data pengukuran viskositas nanoemulsi pada penyimpanan selama 12 minggu suhu kamar

\begin{tabular}{|c|c|c|c|c|c|c|c|c|c|c|c|c|c|}
\hline \multirow{2}{*}{ Formula } & \multicolumn{10}{|c|}{ waktu (minggu) } \\
\cline { 2 - 14 } & 0 & 1 & 2 & 3 & 4 & 5 & 6 & 7 & 8 & 9 & 10 & 11 & 12 \\
\hline 1 & 100 & 100 & 113 & 113 & 125 & 150 & 200 & 225 & 250 & 275 & 325 & 400 & 450 \\
\hline 2 & 113 & 113 & 125 & 125 & 225 & 225 & 250 & 300 & 300 & 325 & 375 & 450 & 475 \\
\hline 3 & 150 & 150 & 225 & 225 & 275 & 275 & 300 & 325 & 350 & 450 & 475 & 475 & 500 \\
\hline
\end{tabular}

\section{Uji sentrifugasi}

Pada uji sentrifugasi semua sediaan nanoemulsi tidak terjadi pemisahan, pengkriman, dan kekeruhan. Sedangkan pada sediaan emulsi yang dalam hal ini sebagai pembanding, sediaan tersebut terjadi pengkriman dan juga pemisahan setelah disentrifugasi selama 5 jam. Hal ini dapat dilihat pada dilihat pada Gambar 2 dan Gambar 3.
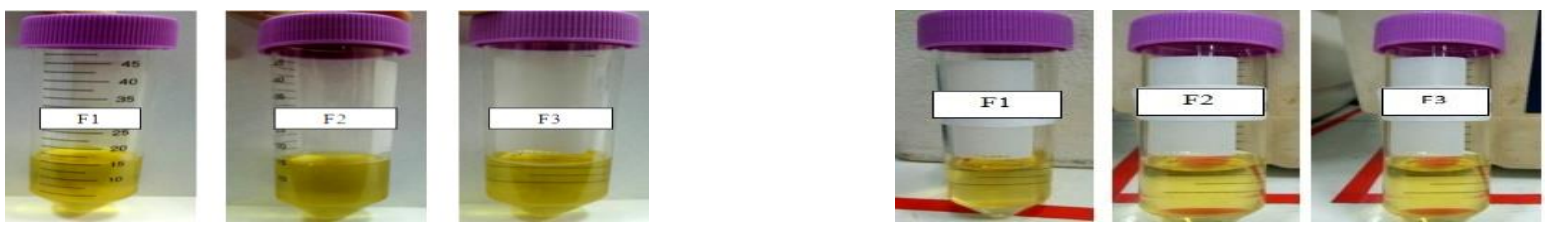

Gambar 2. a. Nanoemulsi sebelum disentrifugasi selama 5 jam, b. Nanoemulsi setelah disentrifugasi selama 5 jam
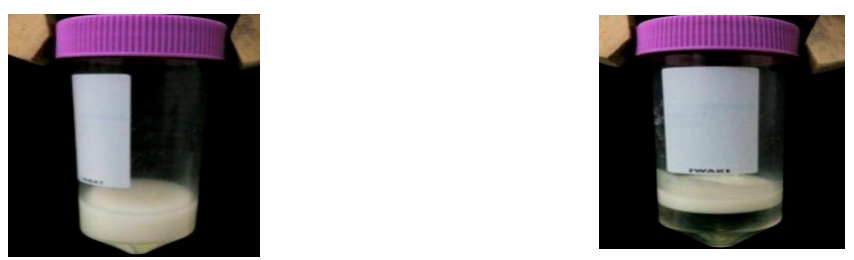

Gambar 3. a. emulsi sebelum disentrifugasi selama 5 jam, b. emulsi setelah disentrifugasi selama 5 jam.

\section{Pengukuran ukuran partikel dan analisa TEM}

Rata-rata ukuran partikel nanoemulsi pada 0 minggu, 6 minggu, dan 12 minggu penyimpanan suhu kamar dapat dilihat pada Tabel 4 dan hasil analisa TEM dapat dilihat pada Gambar 4.

Tabel 4. Data penentuan ukuran partikel nanoemulsi pada penyimpanan 12 minggu pada suhu kamar

\begin{tabular}{|l|l|l|l|}
\hline \multicolumn{2}{|l|}{ Rata-rata ukuran Partikel (nm) } & 6 Minggu & 12 Minggu \\
\hline Formula & 0 Minggu & 6207,98 \\
\hline F1 & 262,03 & 861,67 & 2207,90 \\
\hline F2 & 189,82 & 449,65 & 605,29 \\
\hline F3 & 401,69 & 965,67 & 1047,84 \\
\hline
\end{tabular}




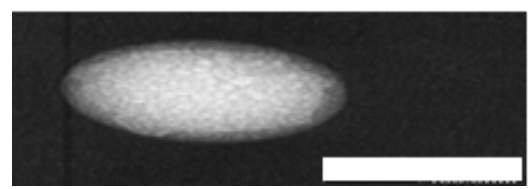

Gambar 4. Hasil analisa morfologi partikel nanoemulsi F2 dengan TEM

Ukuran partikel terkecil nanoemulsi adalah $189,82 \mathrm{~nm}$ sedangkan pada emulsi ukuran pertikel yang diperoleh adalah 1410,80 nm dan pada analisa TEM sediaan nanoemulsi diperoleh bahwa sediaan tersebut memiliki bentuk yang spheris dengan ukuran partikel yaitu $100 \mathrm{~nm}$.

Uji efektivitas anti-aging

Berdasakan hasil pengujian diperoleh bahwa kedua sediaan mempunyai aktivitas anti-aging yang ditunjukkan dengan adanya pengecilan pori, peningkatan kadar air, berkurangnya jumlah noda, meningkatnya kehalusan kulit, dan berkurangnya jumlah kerutan yang ada pada kulit. Namun dalam hal ini nanoemulsi memliki aktivitas antiaging yang lebih baik dari emulsi. Hal ini dapat dilihat pada Tabel 5, Tabel 6, Tabel 7, Tabel 8.

Tabel 5. Data pengukuran kadar air kulit sukarelawan

\begin{tabular}{|l|c|c|c|c|c|}
\hline \multicolumn{7}{|c|}{ Rata-Rata Kadar Air } \\
\hline Formula & 0 Minggu & 1 Minggu & 2 Minggu & 3 Minggu & 4 Minggu \\
\hline Nanoemulsi & 28,7 & 32,2 & 34,8 & 36,8 & 39,2 \\
\hline Emulsi & 28,5 & 30,7 & 32,8 & 34,5 & 35,8 \\
\hline
\end{tabular}

Keterangan: Dehidrasi 0-29; Normal 30-50; Hidrasi 51-100 (Aramo, 2012)

Tabel 6. Data pengukuran pori (pore) sukarelawan

\begin{tabular}{|l|c|c|c|c|c|}
\hline \multicolumn{7}{|c|}{ Rata-rata kadar air } \\
\hline Formula & 0 Minggu & 1 Minggu & 2 Minggu & 3 Minggu & 4 Minggu \\
\hline Nanoemulsi & 56,3 & 38,7 & 29,2 & 22,3 & 15,0 \\
\hline Emulsi & 58,2 & 42,2 & 34,5 & 28,8 & 22,7 \\
\hline
\end{tabular}

Kecil 0-19; Beberapa besar 20-39; Sangat besar 40-100 (Aramo, 2012)

Tabel 7. Data pengukuran noda (spot) sukarelawan

\begin{tabular}{|l|c|c|c|c|c|}
\hline \multicolumn{7}{|c|}{ Rata-rata kadar air } \\
\hline Formula & 0 Minggu & 1 Minggu & 2 Minggu & 3 Minggu & 4 Minggu \\
\hline Nanoemulsi & 44,3 & 38,0 & 29,3 & 23,0 & 17,2 \\
\hline Emulsi & 44,0 & 38,2 & 31,0 & 26,7 & 21,7 \\
\hline
\end{tabular}

Keterangan: Sedikit 0-19; Beberapa noda 20-39; Banyak noda 40-100 (Aramo, 2012)

Tabel 8. Data pengukuran kerutan (wrinkle) sukarelawan

\begin{tabular}{|l|c|c|c|c|c|}
\hline \multicolumn{7}{|c|}{ Rata-rata kadar air } \\
\hline Formula & 0 Minggu & 1 Minggu & 2 Minggu & 3 Minggu & 4 Minggu \\
\hline Nanoemulsi & 45,8 & 37,0 & 23,2 & 17,3 & 11,2 \\
\hline Emulsi & 46,2 & 37,8 & 30,3 & 23,8 & 18,8 \\
\hline
\end{tabular}

Keterangan: Tak berkeriput 0-19; Berkeriput 20-52; Berkeriput parah 53-100 (Aramo, 2012). 


\section{Pembahasan}

Sediaan nanoemulsi merupakan salah satu bentuksediaan yang stabil, dan jernih. Adanya fenomena creaming yang ditunjukkan pada nanoemulsi formula F1dikarenakan adanya pembentukan agregat yang lebih besar yang memiliki kecendrungan untuk naik keatas [8]. Perubahan $\mathrm{pH}$ pada sediaan hal ini dikarenakan komposisi pada sediaan terdiri dari minyak zaitun yang sebagian besar terdiri asam lemak tak jenuh, dan jika terhidrolisis akan menghasikan asam karboksilat yang memungkinkan terjadinya penurunan $\mathrm{pH}$ pada sediaan akan tetapi penurunanpH masih berada pada rentang $\mathrm{pH}$ kulit [9]. Peningkatan viskositas pada sediaan terjadi dikarenakan adanya pengaruh dari konsentrasi surfaktan yang digunakan dan disebabkan oleh adanya flokulasi yang terjadi antar partikel yang terdispersi sehingga menyebabkan viskositas sediaan meningkat [8]. Uji sentrifugasi menggambarkan kestabilan sediaan karena pengaruh gravitasi bumi setara dengan satu tahun. Nanoemulsi merupakan sediaan stabil dikarenakan pada nanoemulsi tidak adanya pemisahan dengan sentrifugasi [8] dan ukuran partikel yang kecil dari nanoemulsi dikarenakan adanya penggunaankonsentrasi surfaktandan kosurfaktan dapat menurunkantegangan permukaan karenaadanya peningkatan absorpsisurfaktan diantara minyak-airsehingga memperkecil ukuranglobul dari sediaan nanoemulsi. Selain itu,energipengadukan juga cenderung menghasilkanpenurunan ukuran globul [10].

Pada uji efektivitas terlihat bahwa sediaan emulsi mempunyai kemampuan untuk mengurangi skin aging dengan cara meningkatkan kadar air di kulit sehingga kulit menjadi lembab, mengecilkan pori-pori kulit, mengurangi noda, dan mengurangi jumlah keriput kulit. Hal ini dikarenakan adanya vitamin E yang terdapat pada minyak zaitun yang mana vitamin E berfungsi sebagai pelembab, dan dapat melepaskan sel kulit mati sehingga dapat mengecilkan poripori kulit $[11,12]$. Namun dalam hal ini nanoemulsi F2 lebih efektif dibandingkan emulsi dikarenakan ukuran partikel yang kecil dari nanoemulsi sehingga dapat menembus lapisan kulit dengan mudah dan absorbsi zat aktif menjadi lebih banyak yang menyebabkan aktivitas anti-aging nanoemulsi menjadi lebih baik dari emulsi.

\section{Kesimpulan dan Saran}

Minyak zaitun ekstra murni yang diformulasikan menjadi sediaan nanoemusi lebih stabil bila dibandingkan sediaan emulsi makro. Kestabilan nanoemulsi dapat ditandai dengan tidak terjadi perubahan secara organoleptik dan tidak terjadinya pemisahan fase secara irreversibel.

Efektivitas anti-aging sediaan nanoemulsi minyak zaitun ekstra murni lebih baik daripada sediaan emulsi. Hal ini ditandai dengan adanya peningkatan kadar air, pengurangan jumlah noda, dan kerutan, dan pengecilan pori yang lebih besar dibandingkan dengan sediaan emulsi.

Saran penulis untuk peneliti selanjutnya adalah menggunakan bahan aktif tambahan yang mempunyai khasiat anti-aging agar efektivitas anti-aging pada kulit lebih maksimal dan selanjutnya agar dilakukan pengujian secara in-vitro dan in-vivo terhadap sediaan nanoemulsi minyak zaitun ekstra murni.

\section{Daftar Pustaka}

[1] Sharma, H., Sahu, G., dan Sahu, S. (2014).A Review Of Current And Novel Trends For Anti-Ageing Formulation. International Journal Of Pharmaceutical, Chemical, And Biological Sciences. 4(1): 118-121.

[2] Owen, R. W. (2000). Olive-oil Consumption and Health: The Possible Roleof Antioxidants. The Lancet Oncology. 1:107-112.

[3] Mulyawan, D., dan Suriana, N. (2013). A-Z Tentang Kosmetik. Jakarta: Elex Media Komputindo.

[4] Smaoui, S., Hlima, H.B., Jarraya, R., Kamaoun, N.G., Ellou. Foze, R., dan Damak, M. (2012). Cosmetic Emulsion From Virgin Olive Oil: Formulation and Bio-Physical Evaluation. African journal of Biotechnology. 11(40): 9664-9671.

[5] Mondal, S.C. (2015). Ageing and Potential Anti-Aging Phytochemicals: An Over view. Review Article. World Journal Of Pharmacy and Pharmaceutical Science. 4(1): 426-454.

[6] Gupta, P. K., Gupta, S., Pandit, J. K., Kumar, A., dan Sawaroop, P. (2010). Pharmaceutical Nanotechnology Novel Nanoemulsion High Energy Emulsification Preparation, Evaluation and Application. The Pharma Research. 2010(3): 117-138.

[7] Rawlins, E. A. (2002). Bentley's textbook of Pharmaceutics. 18thEdition. London: Bailierre Tindall.

[8] Lachman, L., Lieberman, Herbert, A., Kanig, dan Joseph, L. (1994). Teori dan Praktek Industri Farmasi 1. Edisi III.Terjemahan dari The Theory and Practiseof Industrial Pharmacy, oleh Suyatmi, Siti. Jakarta. UI-Press.

[9] Sastrohamidjojo. (2005). Kimia Dasar. Yogyakarta: Gadjah Mada University Press. 
[10] Salager, J. L., J. M. Andérez, M. I.Briceño, de Sánchez, M. P., and deGouveia M. R. (2002). Formulation and Composition Variables as well as StirringEnergy. Rev. Téc. Ing. Univ.Zulia. 25 (3):16.

[11] Tranggono., Iswari, R., dan Latifah, F. (2007). Buku Pegangan Ilmu Pengetahuan Kosmetik. Jakarta: PT Gramedia Pustaka Utama. Halaman 6-8.

[12] Dreyfuss, D. (2015) How to Make Enlarged Pores Smaller. Tanggal Akses 18 Maret 2017. http://www.dgplasticsurgery.com/howtomake-enlarged-pores -smaller. 